\title{
The Determinants Of Renewable Energy Consumption: An Empirical Analysis For The Balkans
}

\author{
Basak Gul Akar, Assistant Prof. \\ Faculty of Kozan Business Administration, Cukurova University, Turkey \\ doi: 10.19044/esj.2016.v12n11p594 URL:http://dx.doi.org/10.19044/esj.2016.v12n11p594
}

\begin{abstract}
As a measure of development, energy has a priority in economic literature. However, both economic and social costs caused by traditional energy sources have led to question on the importance of these resources. In addition to this, various problems such as pollution and dependence on foreign energy has brought about new researches instead of existing energy sources. Alternative and renewable energy sources, which are named as "clean energy", are expected to take the place of the old method. However, there are many factors affecting the use of new energy sources. These factors include energy prices, energy production, energy dependence, economic growth, trade openness, and the use of carbon dioxide. Besides, development levels of countries have a significant influence on the degree of interaction between these factors.

In the present study, firstly, renewable energy consumption and the determinants of this energy use were discussed in the theoretical context. Consequently, the required empirical tests were applied for Balkan countries - Albania, Bosnia-Herzegovina, Bulgaria, Croatia, Montenegro, Kosovo, Macedonia, Romania, Serbia, Slovenia, Turkey, and Greece. Dynamic panel data method was preferred for analysis. However, this panel covers a period between the years of 1998-2011. According to the results obtained through a dynamic panel data analysis, it was found that there is a negative and statistically significant relationship between economic growth and renewable energy consumption. On the other hand, trade openness and natural gas rents are determined to have a positive effect on renewable energy consumption in the Balkans.
\end{abstract}

Keywords: Renewable energy, economic growth, trade openness, natural gas, The Balkans 


\section{Introduction}

Energy is a strategic resource that influences the outcomes of wars and fuel, hindering economic development as well as cleaning and polluting environment. However, no matter the way energy it is used (such as power generation, industrial use, transportation, and residential use), it constitutes a basis for economic growth and prosperity. As countries grow and wealth increases, their demand on energy increases as well. Thus, a rapid growing demand for energy during the globalization process, and the countries' dependence on energy indicate that energy would be a major problem in the next century (Saidi \& Hammami, 2015).

The majority of energy demand is usually met through the importation of fossil fuels. Nevertheless, it causes several problems that countries face today. Some of these problems are: i) Cost increase in energy prices; ii) Population growth; iii) An increase in energy density per person; iv) Environmental problems. Therefore, the significance of energy infrastructure investments emerges with a view of alleviating these problems and in meeting the current energy demand. Thus, it poses an opportunity for the expansion of the renewable energy (RW) sector (Zawaydeh, 2015; Sadorsky, 2009).

RW maintains various advantages which are: it is accessed easily; it has a large distribution area; it is not pro-carbon and inexhaustible. Hence, the advantage of RW being not pro-carbon is highly put into consideration. The most important potential environmental problems related to energy are greenhouse effect. An increase in these gases causes a rise in the Earth's surface heat. Also, an increase in sea level leads to serious dangers. A solution to this danger is a more reliable and cleaner energy investments and energy resources. Subsequently, investment in RW technology is expected to be nearly doubled in 2030 (from \$ 270 billion in 2014 to $\$ 400$ billion in 2030). Taking the right steps is vital to the investment. Therefore, the key point is to have a long-term de-carbonization perspective as well (IEA, 2015; Dinçer, 2000; Ackah \& Kizys, 2015).

In order to lessen the effects of climate change and reduce fossil fuel dependence and the negative effects of it on global warming, renewable energy sources (RWS) promotion such as wind, sunlight, geothermal, waves and waste has become a major issue of concern for most European Union (EU) countries. In this regard, most EU countries have endorsed the inclusion of RWS in development initiatives (Karakosta et al., 2012). Likewise, the World Bank lays an emphasis on the idea that clean energy and activities are key factors for reducing poverty and fostering economic growth especially in rural areas. However, the negative environmental impacts of energy use must be taken into account in all these points. This is because a large portion of the consumed energy brings about the release of greenhouse 
gases. Thus, two issues have emerged: energy efficiency and renewable energy consumption RWC (Ackah \& Kizys, 2015).

The main objective of this study is to investigate the significance of RWC for Balkan countries. Balkan countries have a great natural potential and geography for renewable energy sources (sunlight, wind, rain, waves, etc.). However, much more evidence is needed so as to determine the availability or why they cannot be used. Today, various programs operate for the use of clean energy sources. Balkans Renewable Energy Program initially implemented in Albania, Bosnia-Herzegovina, and Macedonia has been considered as one of the most significant programs. The existing regional programs were expanded in 2012, and now, it includes Serbia, Kosovo, and Montenegro. The aim of this program is to develop the market for RW in the region. Thus, this serves as a means of supporting environmental economics, energy diversification, and the countries' path towards the European Union. Electricity production in the Balkans is mainly based on coal fire at present. Moreover, it is impossible for all countries to meet their electricity needs with domestic power resources. Along with transportation costs, energy supply is predominantly met through imports. However, Balkans has great natural sources and potentials which can be used as a source of electricity consumption (www.ifc.org).

Furthermore, Bosnia-Herzegovina (B-H) has a considerable energy density compared to the developed EU countries. However, 70\% of electricity production is met through coal-fired thermal power plants in Bosnia-Herzegovina. Thus, this made Bosnia-Herzegovina one of the few electricity exporters in the region. The market for oil and its derivatives is open; thus, it tries to facilitate full capacity conditions. Revealing the current situation with figures is insufficient for changing the result. Despite the negative effects of non-renewable energy sources, RW strategy cannot be implemented due to obstacles such as inefficient legal framework, general targets, complex administrative procedures, and incomplete regulatory mechanism (Karakosta et al., 2012). Bosnia-Herzegovina is just one of these examples. In spite of the same geographical richness, we have observed that the use of RES is restricted in all Balkan countries. Therefore, the present study aims to make an assessment through handling the issue from an economical perspective.

System-GMM method was used for the empirical application in which dynamic panel data analysis is preferred. Through this study, the determinants of renewable energy consumption for Balkan countries in the years 1998-2011 is expected to contribute to literature in terms of region, model, and method. Having examined the studies on this subject, econometric analysis will be conducted. Also, the results and policy recommendations will be made available. 


\section{Related Literature}

Subsequently, various results have shown the variables considered in the literature on renewable energy. We realize that various factors such as the development level of countries, geographical conditions, political structure etc. lead to the existence of differences in results. Within the context of literature examined in accordance with the model used in the study, a chronological order was followed. Thus, this order was without any differentiation according to variables.

Sadorsky (2009) examined relationship between RWC, $\mathrm{CO}_{2}$ emission, and oil prices for G7 countries (1980-2005) through panel cointegration method. Based on the analysis results, it was found that increase in real GDP per capita in the long term and $\mathrm{CO}_{2}$ per capita are the main forces that supports RWC. Therefore, RWC is positively affected by an increase in both driving forces at a high rate. On the other, increase in gasoline prices has a negative impact on RWC. However, this may be due to a decrease in the real price of gasoline in the forecast range period.

Apergis \& Payne (2010) analyzed the relationship between RWC and the growth for 13 countries (1992-2007) in Eurasia via panel co-integration and error correction models. According to the heterogeneous panel cointegration test results, it was determined that there is a long-term relationship between real GDP, RWC, real gross fixed capital formation, and labor force. Depending on the error correction model, bi-directional causality is available between RWC and economic growth both for short and long term. Economic growth and real gross fixed capital has a positive and statistically significant impact on RWC.

Menegaki (2011) examined the relationship between economic growth and RWC for 27 European countries (1997-2007). In this study which is conducted using panel data analysis, no causality was found between GDP and RWC. On the other hand, the causal link between $\mathrm{CO}_{2}$ Employment-RWC was obtained. In addition, work is an interesting findings obtained in the GDP. Therefore, $\mathrm{CO}_{2}$ is increasing much more than RWC. The reason behind this is the high cost of RW investment. This makes RWC less able to compete than $\mathrm{CO}_{2}$. Menegaki (2011) revealed that an increase in RWC will reduce CO2. Hence, this is as a result of the competitive relationship between $\mathrm{RWC}$ and $\mathrm{CO}_{2}$.

In a study conducted on the European Union countries (1990-2004), Bengoche and Faet (2012) stated that an increase in carbon emissions leads to a rise in renewable energy supply.

On the other hand, in an analysis carried out by Karakosta et al. (2012), it was emphasized that partially established corporate energy framework is required to be strengthened for Bosnia-Herzegovina and 
Serbia. However, Serbia is functioning much more in an effective theoretical framework.

Furthermore, Apergis \& Payne (2012) examined the relationship between renewable and non-renewable energy consumption, and economic growth through panel error correction model for 80 countries (1990-2007). The results indicate that there is a bi-directional causality between three variables in both short and long term. Thus, both types of energy are substantial for economic growth. On the other hand, economic growth has also increased the use of these two energy sources. Besides, substitution between the two energy sources has drawn much attention. This is based on the fact that renewable energy consumption has a negative impact on nonrenewable energy consumption.

In parallel to Apergis \& Payne (2012)’s study, Tugcu et al. (2012) performed their study on G7 countries (1980-2009). In their analysis, autoregressive distributed lag approach has been preferred. Meanwhile, the study which examines the causal relationship between energy consumption and economic growth shows that there is no causal relationship between RWC and GDP in countries such as France, Italy, Canada, and the USA. On the other hand, bi-directional causality was found in both countries, Britain and Japan. In line with our study, uni-directional causality between GDP and RWC in Germany was found. Long-term forecasts indicate that both renewable and non-renewable energy consumption have a great significance for economic growth.

In a study conducted by Omri \& Nguyen (2014), the determinants of RWC were investigated for 64 countries (1990-2011). Hence, this was done using dynamic panel data analysis. It is likely to mention that oil prices have a small negative effect on RWC depending upon the analysis made for high, medium, and low income groups. Changes in the level of income per capita have a significant effect on low and high income levels. On the other hand, no relationship was found for middle-income. The trade openness was also determined to have a statistically significant effect for the other income groups except for the highest income levels. An increase in $\mathrm{CO}_{2}$ seems to have an impact in increasing RWC for all groups of countries. In order to reduce carbon emissions, government's tax fossil fuel is shown as a solution proposal.

Nasreen \& Anwar (2014) found out that there is a long-term bi-directional causality between GDP, trade openness, and energy consumption as a result of panel co-integration and causality tests for 15 Asian countries (1980-2011). While increase in income and trade openness raises energy consumption, it was observed that increase in oil prices except for a few selected countries reduces energy consumption. 
Shearer et al. (2014) have examined the effect of energy supply on RWC and $\mathrm{CO}_{2}$ in the US. The study which covers 2013-2055, investigated future energy demand. Shearer et al. (2014) suggest that the use of renewable energy technologies is delayed by the increasing of natural gas. As such, this may lead to a slowdown in carbon reduction. Also, large amounts of natural gas will not significantly decrease greenhouse gas emissions. However, this can be achieved only with climate policies.

Omri et al. (2015) analyzed RWC and its drivers. Thus, panel data analysis was conducted for 64 countries (1990-2011). In the study which was analyzed depending on high, middle, and low income groups, it was found that an increase in the level of $\mathrm{CO}_{2}$ and GDP leads to an increase in RWC. High levels of carbon emissions will create a demand for a cleaner environment, and will encourage the use of alternative RWC. However, it was indicated that the price of oil slightly affects RWC. Accordingly, it can be considered that RWC is not a full alternative for crude oil at least for now.

Naeimi et al. (2015) have found a positive relationship between economic welfare and renewable energy for Iran (1971-2011). This was done by using the method of Artificial Neural Networks. It was stated that an increase in renewable energy is associated with a decrease in fossil fuel dependency. Thus, these fuels are exported to rich countries and the income will be used for other objectives. For instance, the production of goods and services gives rise to the enhancement of economic prosperity. However, Naeimi et al. (2015) defines that a negative relationship is also possible between energy consumption and income for some reasons. Cost factor is one of the most significant ones. Households are sensitive to prices. As a result, the initial expenses of RWC are high. Households will prefer cheaper traditional type of energy if they have to pay more for energy consumption in the form of heating or lighting obtained from RW. Another reason is that some energy policies should be implemented so as to support RWC. Therefore, acting coordinately and consistently while implementing policies concerning new legislation, subsidies, or incentives, will help in achieving the best result.

Ackah \& Kizys (2015) investigated green energy in oil-producing African countries by means of panel data analysis method for the period of 1985-2010. They indicated that the main dynamics of RWC are GDP per capita, per capita consumption of energy resources, per capita carbon emission, and energy prices. The results illustrated that per capita GDP and energy consumption have a significant positive effect upon RWC. However, the effects of carbon emission and energy prices are negative and statistically insignificant.

Jebli \& Youssef (2015) used panel co-integration method to explain causality between international trade, renewable and non-renewable energy 
consumption, and output for 69 countries (1980-2010). According to Granger causality test results, uni-directional relationship occurs from RWC towards trade in the short term. However, there is a bi-directional relationship in the long run between these parameters. Results indicate that increase in export and import stimulates RWC. While no causality exists between output and RWC in the short run, bi-directional relationship exists in the long run. Besides, the study reveals causality from non-renewable energy consumption to renewable energy consumption. Thus, it is not stated for the other way. It is mentioned in the study that an increase in trade will make contribution to a decrease in greenhouse gas emission. This is achieved by taking into consideration the positive effect of trade on RWC and RW technology transfer. An energy policy which aims to increase the share of RW in the total energy consumption will be effective in decreasing greenhouse gas emission.

However, Saidi \& Hammami (2015) studied the influence of $\mathrm{CO}_{2}$ and economic growth upon energy consumption for 58 countries (1990-2012) using dynamic panel data analysis. It was obtained that there exists a positive and statistically significant relationship between all variables. Thus, an increase in GDP and $\mathrm{CO}_{2}$ raises the energy consumption.

Doğan \& Seker (2016) analyzed the relationship between $\mathrm{CO}_{2}$, real output, renewable and non-renewable energy, and trade and financial development via the method of Environmental Kuznets Curve (EKC). According to a study that includes the best countries (23 countries) within Renewable Energy Country Attractiveness Index (1980-2011), the use of non-renewable energy causes environmental deterioration. It is clear that non-renewable energy resources are less costly than renewable energy resources for now. However, cheaper and less costly production techniques should be explored for RWS. On the other hand, both trade openness and net environmental impact of financial development is positive and reduces environmental pollution. The countries included in the analysis also benefit from the technology emission through both of these instruments. This is a possible reason for the export of non-energy-intensive and environmentally friendly products. It also entails the import of totally opposite ones from the countries where RW's are best used.

\section{Data and Empirical Methodology}

Considering the determinants of renewable energy consumption, empirical application has adhered to the general literature. Based on the study of Omri \& Nguyen (2014), the model on the factors which affect renewable energy consumption has been the key for econometric application. Besides, in the current study, the effect of natural gas has been taken into account unlike previous studies. Thus, the relationship between the 
renewable energy and natural gas consumption which are the substitutions of one another has been considered. The present study is expected to contribute to the literature in terms of both covering Balkan countries and methodology. In this study, a dynamic panel data analysis was performed through Generalized Method of Moments (GMM). Thus, this study preferred the system-GMM method. The reason why dynamic panel data analysis is generally chosen is that this estimator method exploits the endogeneity problem which is likely to occur between errors and explanatory variables, as well as biased parameters (Arellano \& Bond, 1991). In addition, GMM (Generalized Method of Moments) estimators are used to resolve the problem in panel data analysis; however, the length of time is to be short (Arellano \& Bond, 1991; Blundell \& Bond, 1998). It is recommended that dependent and independent variables should be used as tools in order to resolve the endogeneity problem for the models created through taking the difference. Meanwhile, the accuracy of the instruments is tested via Sargan test, while the coefficients estimated and the validity of the model is verified through Wald test which is done in order to check simultaneous significance of the estimators. Another significant issue which needs to be taken into account is that the generalized moments estimator becomes active only if the autocorrelation of the second order does not exist $\left(\mathrm{E}\left[\Delta u_{i, t} \Delta u_{i, t-2}\right]=0\right)$ (Baltagi, 2005).

Consequently, renewable energy consumption is modeled as a function of explanatory variables available in the equation 1 :

$\mathrm{RWC}=\mathrm{F}\left(\mathrm{CO}_{\mathrm{i}, \mathrm{t}}, \mathrm{GDP}_{\mathrm{i}, \mathrm{t}}, \mathrm{OR}_{\mathrm{i}, \mathrm{t}}, \mathrm{TO}_{\mathrm{i}, \mathrm{t}}, \mathrm{NG}_{\mathrm{i}, \mathrm{t}}\right)$

Eq. (1) can be rewritten in a panel data form as growth rate:

$\mathrm{gRWC}_{\mathrm{i}, \mathrm{t}}=\alpha_{0}+\alpha_{1} \mathrm{gCO}_{\mathrm{i}, \mathrm{t}}+\alpha_{2} \mathrm{gGDP}_{\mathrm{i}, \mathrm{t}}+\alpha_{3} \mathrm{gTO}_{\mathrm{i}, \mathrm{t}}$

$$
+\alpha_{4} \mathrm{OR}_{\mathrm{i}, \mathrm{t}}+\alpha_{5} \mathrm{NG}_{\mathrm{i}, \mathrm{t}}+\varepsilon_{\mathrm{i}, \mathrm{t}}
$$

Accordingly, our empirical model can be stated in terms of systemGMM method as shown in Eq (3):

$$
\text { gRWC }_{\mathrm{i}, \mathrm{t}}=\alpha_{0} \mathrm{gRWC}_{\mathrm{i}, \mathrm{t}-1}+\sum_{j=1}^{4} \beta X_{i, t}^{\prime}+\mu_{\mathrm{i}, \mathrm{t}}+\varepsilon_{\mathrm{i}, \mathrm{t}}
$$

Dependent variable and explanatory variables in equations 1,2 and 3 are respectively as follows:

Renewable energy consumption is the share of renewable energy in total final energy consumption (RWC-\% of total final energy consumption);

$\mathrm{CO} 2$ emissions in metric tons per capita (CO2);

Per capita GDP (GDP);

Trade openness is the sum of exports and imports of goods and services measured as a share of gross domestic product (TO-\% of GDP);

Oil rents are the difference between the value of crude oil production at world prices and total costs of production (OR-\% of GDP); 
Natural gas rents are the difference between the value of natural gas production at world prices and total costs of production (NG-\% of GDP)

The country-specific effects $(\boldsymbol{\mu})$

The error term ( $)$

"g" indicates that the variables are expressed in terms of growth rate. variables.

$\boldsymbol{\alpha}_{\mathbf{0}}$ is the parameter to be estimated and $\mathbf{X}$ is a vector of explanatory

Within the model presented in equation 3, i and t refer to countries and time period, respectively. The present study is based upon Balkan countries. However, relevant countries include: Albania, BosniaHerzegovina, Bulgaria, Croatia, Macedonia, Romania, Slovenia, Turkey, Greece, Serbia, Kosovo, and Montenegro. However, Serbia, Kosovo, and Montenegro were excluded from the application as no data were found for this period. In addition, 9 countries were included in the application. Accordingly;

$$
\mathrm{i}=1, \ldots . ., 9 \text { and } \mathrm{t}=1997, \ldots . ., 2011 \text { are referred as such. }
$$

Therefore, the sample period covers annual data from 1998 to 2011. The raw data have been collected from The World Bank's World Development Indicators. Per capita GDP is based upon 2005 prices. RWC, CO2, GDP, and TO are measured in the growth form. This is because these series are not stationary in levels. Nonetheless, OR and NG are stationary in their level forms. As a result, there is no need to convert them. All the predictions were made via Stata program.

Descriptive statistics for each of the variables available in the related model is presented in Table 1.Table 1. Descriptive Statistics

\begin{tabular}{|cccccc|}
\hline \multicolumn{7}{|c|}{ Mariable } & Observation & Mean & Std.Dev. & Min & Max \\
\hline grwc & 126 & .0155169 & .1290324 & -.3193014 & .5454486 \\
\hline gco2 & 126 & .0218871 & .0957176 & -.1547769 & .7137486 \\
\hline or & 126 & .4392661 & .7251489 & 0 & 3.855837 \\
& & & & & \\
\hline ggdp & 126 & .0358497 & .0426947 & .0888545 & .157058 \\
\hline gto & 126 & .3789894 & 4.321546 & -.9472362 & 48.47246 \\
\hline ng & 126 & .3248682 & .7293277 & 0 & 4.051407 \\
\hline
\end{tabular}

\section{Empirical Results}

\section{Unit Root Test Results}

The results from unit root tests are given in Table 2 . The first difference of the series is required not to contain unit roots. In the study conducted for Balkan countries, unit root tests will be conducted based on IPS (Im et al., 2003). According to IPS (Im et al., 2003) unit root test, series are stationary in level. 
Table 2. The Results of IPS Panel Unit Root Tests

\begin{tabular}{|l|l|l|}
\hline & \multicolumn{2}{|c|}{ Level } \\
\hline Variables & IPS Values & $\begin{array}{l}\text { Probability } \\
\text { Values }\end{array}$ \\
\hline gRWC & $-5.89875^{* *}$ & 0.0000 \\
\hline gCO2 & $-7.99608^{* *}$ & 0.0000 \\
\hline gGDP & $-2.62874^{* *}$ & 0.0043 \\
\hline OR & $-2.46091^{* *}$ & 0.0069 \\
\hline gTO & $-6.46989^{* *}$ & 0.0000 \\
\hline NG & $-1.92002^{* *}$ & 0.0274 \\
\hline
\end{tabular}

Notes: Critical values for the IPS test are obtained (Im et al., 2003). In determining the optimal lag, Schwarz information criterion was used. The asterisk indicates the significance at the level of $(* *) 5 \%$.

Table 3. Two-Step Difference-GMM Panel Estimation Results

\begin{tabular}{|l|l|l|}
\hline Dependent variable & Statistic & Prob. \\
\hline & & \\
\hline $\begin{array}{l}\text { Renewable energy consumption } \\
\text { (first lag) }\end{array}$ & -3.28415 & $0.013^{* *}$ \\
\hline Per capita CO2 emissions & 0.61730 & 0.235 \\
\hline Per capita GDP & -5.24804 & $0.002^{*}$ \\
\hline Trade openness & 0.00552 & $0.020^{* *}$ \\
\hline Oil rents & -0.02014 & 0.499 \\
\hline Natural gas rents & 0.06888 & $0.034^{* *}$ \\
\hline Constant & 0.25089 & $0.034^{* *}$ \\
\hline \multicolumn{2}{|l|}{} \\
\hline Diagnostic Tests & Statistic & Prob. \\
\hline Chi-square & 41.3795 & 0.000 \\
\hline AR2 test (p-value) & -1.49156 & 0.135 \\
\hline Sargan & 0.37460 & 1.000 \\
\hline $\begin{array}{l}\text { Notes: The AR2 test is the Arellano-Bond test for the existence of the second-order } \\
\text { autocorrelation in the first differences. The asterisks (*, **, and ***) indicate significance } \\
\text { at the 1\%, 5\% and 10\% levels, respectively. }\end{array}$ \\
\hline
\end{tabular}

In system-GMM analysis, Wald test is done for the estimators' simultaneous significance control. The null hypothesis (H0) indicates that all variables are equal to zero. According to the Wald test results, the null hypothesis is rejected at the $1 \%$ level of significance. In other words, alternative hypothesis $\left(\mathrm{H}_{1}\right)$ refers to the fact that they have an impact on the dependent variable. Therefore, the estimated coefficients and the validity of the model are verified. Besides, Sargan test examines the validity of the test instruments. Hence, we cannot reject $\mathrm{H}_{0}$ hypothesis (over identifying restrictions are valid). With Arellano-Bond test, it has been investigated whether error term includes second order autocorrelation or not. 
The obtained results reveal that none of the models has the second-order autocorrelation.

The system-GMM estimation results which are performed for the Balkan countries are presented in Table 3. The results reveal that GDP has a negative and statistically significant impact on RWC at the $1 \%$ level. As for the relationship between trade openness and natural gas rents with renewable energy consumption, positive and statistically significant results were obtained at the 5\% level. However, per capita CO2 emissions and oil rents are not found to have a statistical and significant effect on the renewable energy consumption.

\section{Conclusion and Policy Recommendations}

"The cheapest energy is the saved energy" that is possible to summarize this issue. Renewable energy sources do not only provide the means of saving the energy, but also to regain it. From an economic perspective, renewable energy technology is seen as a cost factor. However, it amortizes itself. Thus, what it provides in the long-run are ignored. Furthermore, just dealing with the economic dimension is not true. However, this means to avoid a highly significant detail, sustainable development.

Development constitutes economic growth and environmental progress. In this sense, the fact that RW is environment friendly at the highest rank is indisputable. However, the countries in the world do not follow appropriate policies towards the facts. Many negative effects of greenhouse gas emissions are overlooked because of low costs. Yet, nature always reveals its policies. It has its own rules and characteristics. Therefore, if it contradicts with nature, we will not probably live in a clean environment that embraces us. The Balkans rests on geography with clean environment. Therefore, countries which have renewable energy sources in this region should immediately utilize technologies in accordance with these sources.

Subsequently, the results from the dynamic panel data model indicate that GDP has a negative and statistically significant effect on RWC. Although this finding appears contrary to the general literature, it is not surprising for the Balkan countries. In this region where the energy is imported mostly and is mainly dependent on coal, RWC can be reduced by increasing the level of income. The primary reason is the level of development of the region. RW requires costly technology. As such, the initial expenses of RW investments are very high. This case causes the continuation of traditional energy consumption. Existing economic growth, unfortunately, may not be sufficient to provide fund for RW. In addition, we conclude that household, especially, is unwilling to spend their income for energy consumption acquired from expensive heating or lighting as a usual 
result. The related study which belongs to Naeimi (2015) clarifies this perspective of households.

By contrast with GDP, trade and natural gas rents influence RWC positively and shows statistical significant. However, the impact of trade is very small, but it should not be ignored. Although its power is limited, higher trade increases RWC. Therefore, authorities should take steps to enhance trade. It is thought that the driving force behind the positive relationship between NG and RCW is imported NG. It is a stimulant to use more renewable energy. Being an expensive energy source of natural gas will result in using RWS whose owner are the Balkans. No matter the initial cost of RW, the Balkan countries substantially save on renewable energy in the long run due to its advantages.

However, when these solutions are evaluated within the context of Balkan countries, the issue is slightly deepened. This is because the analysis is owned in countries which covered RWS. While this cannot be converted to energy used, it can be depended on by many other reasons. This may be due to the political and economic structure. Initially, global characteristic of environmental regulations must be considered. Also, obstacles related to the costs should be tried to overcome the support of international organizations. These steps should be accelerated with the support of country governments and other major companies. RW investment of firms should be increased in providing more financial support. In this sense, "green loan" may be a solution. RW project financing can be offered as an option to promote the companies for the use of these energies at low interest rates. Moreover, research and developmental activities should be developed in accordance with RW technology. This is so that low-cost investments can be made economically. It is also recommended that incentives should not be in the form of physical capital, but human capital. Hence, the need for qualified staff that has master engineering is required. The deficit is to be met through increasing the number of students who prefer to study science and mathematics. One of the ways for providing this is to encourage students to receive education on such departments.

In fact, the problem is that we are under the assumption that the world is ours. If we wish to hand down the world to the next generation, we need to create an awareness of renewable energy for a clean environment.

\section{References}

Ackah \& Kizys (2015). Green growth in oil producing African countries: A panel data analysis of renewable energy demand. Renewable and Sustainable Energy Reviews, 50, 1157-1166.

Apergis \& Payne (2010). Renewable energy consumption and growth in Eurasia. Energy Economics, 32, 1392-1397. 
Apergis \& Payne (2012). Renewable and non-renewable energy consumption-growth nexus: Evidence from a panel error correction model. Energy Economics, 34, 733-738.

Arellano \& Bond (1991). Some tests of specification for panel data: Monte Carlo evidence and an application to employment equations. Review of Economic Studies 58, 277-297.

Baltagi (2005). Econometric Analysis of Panel Data (3rd ed.). Chichester: John Wiley \& Sons.

Bengochea \& Faet (2012). Renewable energies and $\mathrm{CO}_{2}$ emissions in the European Union. Energy Sources, Part B: Economics, Planning, and Policy, 7(2), 121-130.

Blundell \& Bond (1998). Initial conditions and moment restrictions in dynamic panel data models. Journal of Econometrics, 87(1), 115-143.

Dinçer (2000). Renewable energy and sustainable development: a crucial review. Renewable and Sustainable Energy Reviews, 4, 157-175.

Dogan \& Seker (2016). The influence of real output, renewable and nonrenewable energy, trade and financial development on carbon emission in the top renewable energy countries. Renewable and Sustainable Energy Reviews, 60, 1074-1085.

Karakosta et al. (2012). Analysis of renewable energy progress in the western Balkan countries: Bosnia-Herzegovina and Serbia. Renewable and Sustainable Energy Reviews, 16, 5166-5175.

Im et al. (2003). Testing for unit roots in heterogeneous panels. Journal of Econometrics, 115(1), 53-74.

International Energy Agency (2015). World Energy Outlook, France.

IFC- International Finance Corporation World Bank Group http://www.ifc.org/wps/wcm/connect/region_ext_content/regions/europe+ middle+east+and+north+africa/ifc+in+europe+and+central+asia/countries/ba lkan+renewable+energy+program+(brep)

03/03/2016.

Jebli \& Youssef (2015). Output, renewable and non-renewable energy consumption and international trade: Evidence from a panel of 69 countries. Renewable Energy, 83, 799-808.

Menegaki (2011). Growth and renewable energy in Europe: A random effect model with evidence for neutrality hypothesis. Energy Economics, 33, 257263.

Naeimi et al. (2015). Forecasting the effect of renewable energy consumption on economic welfare: Using artificial neural networks. International Journal of Management, Accounting and Economics, 2(1), 1025. 
Nasreen \& Anwar (2014). Causal relationship between trade openness, economic growth and energy consumption: A panel data analysis of Asian countries. Energy Policy, 69, 82-91.

Omri \& Nguyen (2014). On the determinants of renewable energy consumption: International evidence. Energy, 72, 554-560.

Omri, Daly \& Nguyen (2015). A robust analysis of the relationship between renewable energy consumption and its main drivers. Applied Economics, 47(28), 2913-2923.

Sadorsky (2009). Renewable energy consumption, $\mathrm{CO}_{2}$ emissions and oil prices in the G7 countries. Energy Economics, 31, 456-462.

Saidi \& Hammami (2015). The impact of $\mathrm{CO}_{2}$ emissions and economic growth on energy consumption in 58 countries. Energy Reports, 1, 62-70.

Shearer et al. (2014). The effect of natural gas supply on US renewable energy and $\mathrm{CO}_{2}$ emissions. Environmental Research Letters, 9, 1-8.

Tugcu et al. (2012). Renewable and non-renewable energy consumption and economic growth relationship revisited: Evidence from G7 countries. Energy Economics, 34, 1942-1950.

Zawaydeh (2015). Energy efficiency, renewable energy targets, and $\mathrm{CO}_{2}$ reductions expected by 2020. Strategic Planning for Energy and the Environment, 35(2), 18-47. 